\title{
La Doctrina Monroe en Buenos Aires. Miradas desde la prensa y la diplomacia mexicana. 1910
}

\section{The Monroe Doctrine in Buenos Aires. Looks from the Press and Mexican Diplomacy. 1910}

\author{
María del Rosario Rodríguez Díaz*
}

Resumen: este artículo se refiere al debate suscitado al interior de la Cuarta Conferencia Panamericana de 1910, celebrada en Buenos Aires, a partir de la iniciativa presentada por Estados Unidos y Brasil que buscaba otorgarle validez jurídica a la doctrina Monroe. Se parte de la premisa de considerar que dicho encuentro interamericano constituía la institucionalización del proyecto de integración liderado por Estados Unidos en el continente americano. A través del análisis del informe de la delegación a la Secretaría de Relaciones Exteriores de México, se reconstruyen las contradicciones y tensiones que se dieron ante el intervencionismo estadounidense en América Latina, en el escenario de la reunión argentina, apoyándose en fuentes hemerográficas surgidas durante los meses de julio y agosto de 1910.

Palabras Clave: Panamericanismo; Doctrina Monroe; México; Prensa.

ABSTRACT: This article refers to the debate that took place within the Fourth Pan American Conference of 1910, held in Buenos Aires based on the initiative presented by the United States and Brazil tended to validated juridical speaking the Monroe Doctrine. It is based on the premise of considering that this meeting constituted the institutionalization of the USA-led integration project in the Americas. Through the analysis of the delegation's report to the Mexican Ministry of Foreign Affairs, we will reconstruct the contradictions and tensions that occurred in the face of American interventionism in Latin America, in the setting of the Argentine meeting, and we will complement the study with hemerographic sources that emerged during the months of July and August 1910.

KeYwoRDS: Panamericanism; Monroe Doctrine; Mexico; Diplomacy; Press.

Recibido: 20 de marzo de 2020

Aceptado: 7 de octubre de 2020

Universidad Michoacana de San Nicolás de Hidalgo (rdiaz@umich.mx). 


\section{INTRODUCCIÓN}

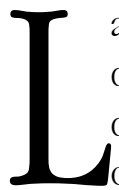

a IV Conferencia Panamericana se desarrolló en medio de focos de tensión en el continente, derivados de la política exterior estadounidense en América Latina, así como la consiguiente resistencia al fortalecido postulado de Monroe a principios del siglo XX. Estudiosos como Carrillo (2018), Morgenfeld (2007) y Elda Pérez (2012) sostienen que en aquella asamblea argentina no se incluirían asuntos que pudieran ocasionar tensiones y confrontaciones entre las naciones americanas e incluso se llega a afirmar que esta tuvo menores alcances que sus antecesoras, debido al bajo nivel de ratificación de las resoluciones adoptadas. ${ }^{1}$ Otros autores la relacionan con los discursos nacionales identitarios, prevalentes en el marco de la celebración del Centenario de la Independencia en Hispanoamérica. ${ }^{2}$ Por su parte, Zusman (2011) incluye la perspectiva cultural y de conservación de los recursos naturales, como una forma de abordar los procesos de legitimación de las políticas imperiales formales e informales. La mayoría de los estudios coinciden en señalar que este Cuarto Encuentro Panamericano tuvo su origen en los afanes estadounidenses por extender su área de influencia comercial hacia el cono sur, espacio tradicionalmente dominado por las potencias europeas.

Indudablemente, la presencia e influencia económica de Gran Bretaña y de otras potencias representaba una amenaza a la seguridad estadounidense. Por nuestra parte, consideramos que las reuniones panamericanas eran encuentros multilaterales, organizados desde Washington con la intención de consolidar su influencia hegemónica en el continente, y apoyados en la American Policy por excelencia: la Doctrina Monroe. De tal manera que el panamericanismo y el monroísmo conforman las dos caras de la política interamericana.

El postulado de Monroe ha sido un tema muy socorrido en la historiografía contemporánea, sin embargo, llama la atención que la mayoría de los trabajos referentes a las conferencias panamericanas no profundizan

1 Para mayor información véanse Veremundo Carrillo 2018; Leandro Morgenfeld 2007.

2 Con relación a este evento véase Alexandra Pita 2017. 
en las implicaciones de este principio político en las relaciones interamericanas y, en particular, tampoco aluden a su significado en el convite panamericano de 1910. ${ }^{3}$ Por ello, en este ensayo nos hemos propuesto reconstruir el debate suscitado a partir de la iniciativa brasileña de respaldar aquella doctrina y conocer la postura asumida por los representantes mexicanos. Así, hemos dividido el texto en dos partes: en la primera abordaremos el significado y las implicaciones del binomio panamericanismo-monroísmo, mientras que en la segunda reconstruiremos, apoyados en la prensa, los posicionamientos de los delegados mexicanos en la reunión de Buenos Aires.

\section{PANAMERICANISMO Y MONROÍSMO}

Desde la Primera Conferencia Panamericana celebrada en Washington en 1889, Estados Unidos puso en marcha un proyecto que buscaba concretar la unidad continental, bajo su égida. Es decir, el panamericanismo desde la óptica estadounidense consideraba todo el continente en una sola unidad bajo su liderazgo. En esta línea, la Doctrina Monroe era el antecedente y fundamento del panamericanismo y ambos se constituyeron en los ejes de la política estadounidense hacia América Latina de fines del siglo XIX y principios del xx.

Por consiguiente, las administraciones de William McKinley, Theodore Roosevelt y Howard Taft desplegaron una política intervencionista e injerencista hacia sus vecinos del sur. En el tránsito de la política del Big Stick a la diplomacia del dólar, el continente americano revestía un significado geopolítico: América Latina se presentaba para Estados Unidos como una zona de contención de rivales extracontinentales.

Fue en este escenario donde, en diciembre de 1905, se emitió el Corolario Roosevelt a la Doctrina Monroe. Este contenía una mezcla de argumentos de corte humanitario, que implicaban la obligación estadounidense de intervenir en los problemas internos de los países latinoame- 
ricanos y asumir el papel de policía continental. El mandatario señaló que veía la necesidad de reafirmar este postulado ante la manifiesta incapacidad de sus vecinos del sur por mantener el orden y que, ante todo, buscaba su bienestar. El Corolario también incluía una advertencia: si una nación demostraba que sabía proceder con razonable eficacia y decencia en cuestiones sociales y políticas, si conservaba el orden y cumplía sus compromisos, no tenía que temer la injerencia estadounidense.

Desde luego, este pronunciamiento despertó reacciones al interior de la Unión Americana en contra de la política de Roosevelt: por un lado se señalaba que Estados Unidos no tenía la capacidad militar de poner en práctica y defender la Doctrina Monroe, por el otro se le atacaba, ya que se pensaba que esa potencia tendría que resolver "los excesos e ineficacias de los estados latinoamericanos" (Perkins 1955: 241).

Contra aquellas expectativas, en Washington consideraban necesario conjurar los constantes conflictos interamericanos por medio de una mejor promoción de las conferencias panamericanas, y lograr así una mayor integración económica y comercial de los países del continente bajo su liderazgo. América Latina era una región donde la Casa Blanca buscaba incidir a través de la conformación de un mercado panamericano y de la firma de acuerdos de cooperación continental. Dicha importancia económico-comercial fue expresada estadísticamente por John Barrett, director de la Oficina Internacional de las Repúblicas Americanas a los delegados estadounidenses que viajarían a Argentina en julio de 1910:

The United States bought from and sold to Latin America in 1909 products valued at the large total of nearly six hundred million dollars (\$600 000000$)$. The exact figures were five hundred and eighty-nine million, three hundred and two thousand dollars (\$589302 000) [...] on the assumption, however, that the raw products of Latin America are needed. In Vast quantities to keep the factories, labor and capital of The United States. ${ }^{4}$

4 "Estados Unidos compró y vendió a América Latina en 1909 productos valorados en un gran total de casi seiscientos millones de dólares (600 000000 de dólares). Las cifras exactas fueron quinientos ochenta y nueve millones, trescientos dos mil dólares (\$589302 000) [...] bajo el supuesto, sin embargo, de que los productos crudos de América Latina son necesarios. En grandes cantidades para mantener las fábricas, 
Por lo que toca al país anfitrión, a comienzos del siglo xx, este experimentaba un grado de desarrollo económico y estabilidad política sobresaliente: sus exportaciones de cereales y de carne a los mercados europeos habían proporcionado bonanza a sus elites económicas, y de este éxito las oligarquías presumieron a los delegados panamericanos.

No resulta fortuito que la política de expansión económico-comercial estadounidense corriese paralela tanto a su expansionismo naval-militar como a la promoción de los encuentros panamericanos durante la primera década del siglo xx. Theodore Roosevelt y Howard Taft buscaban la unión de las repúblicas para favorecer la relación entre los países de América. Asimismo, pretendían la suscripción de tratados y acuerdos que contasen con la anuencia y el respaldo de las elites latinoamericanas que, al actuar de esta manera, se aseguraban a sí mismas el predominio de su estatus socioeconómico y su preeminencia política.

Las Conferencias Internacionales Americanas constituyeron la estrategia, mediante ellas Washington impulsaba proyectos integracionistas en la región, a desarrollarse bajo su tutela. Ejemplo de ello fue la promulgación del mencionado Corolario Roosevelt, a través del cual el vecino del norte se abrogaba el papel de policía continental; por supuesto que exacerbó un sentimiento antiestadounidense y generó que en diversos sectores sociales hubiese pronunciamientos antimperialistas y antimonroístas. ${ }^{5}$ El antiyanquismo se expresó en la obra del rioplatense Manuel Ugarte, cuya voz, en forma de denuncia alarmada, pugnaba por contener la avasalladora marcha estadounidense por encima de los países iberoamerica-

mano de obra y capital de los Estados Unidos" (traducción del editor). Cabe señalar que en la Tercera Conferencia se acordó la conversión de la Oficina de Repúblicas Americanas en una organización ejecutiva. Su función consistiría en relacionarse con los diferentes gobiernos para ratificar tratados y preparar programas para los congresos futuros, entre otras actividades. También se abordó la cuestión del cobro de deudas por la fuerza, ante lo cual el representante argentino Luis Drago enunció su oposición a estas acciones, que se habían vuelto frecuentes; su discurso quedó plasmado en la doctrina que lleva su nombre.

5 Aun en este periodo se llegó a hablar del nacimiento de corrientes político-ideológicas antimperialistas. 
nos. De igual modo, el propio Roque Sáenz Peña destacó como autor de textos contrarios al postulado Monroe, ${ }^{6}$ y así lo ubica el historiador Kosel. Aunque en las Conferencias realizadas en México en 1902 y en la de Río de Janeiro en 1905 se intentó incluir pronunciamientos de adhesión a la Doctrina Monroe, ${ }^{7}$ estos no prosperaron, incluso a pesar del esfuerzo del entonces secretario de Estado, Elihu Root, quien realizó un periplo por territorio latinoamericano, esforzándose por explicar la naturaleza benéfica de la multicitada doctrina:

En muchas partes de América del Sur ha habido malos entendidos de la actitud y propósitos de los Estados Unidos hacia las otras repúblicas americanas. Una idea ha sido la dominante, que el contenido de la doctrina Monroe implicaba una idea de superioridad y el derecho de ejercer cierta protección sobre las naciones en las que la doctrina se aplica. Esto no es verdad, sin embargo, tal impresión continúa siendo una barrera para un buen entendimiento [...] para la introducción de los capitales estadounidenses y la expansión comercial (1917: 272).

No obstante la reticencia de sus vecinos del sur, para Estados Unidos era importante conseguir un pronunciamiento colectivo que reconociese la validez jurídica de esta doctrina en el Derecho internacional. ${ }^{8}$ En este sentido, el Iv Encuentro Interamericano revestía particular relevancia en el actuar exterior de Washington, ya que buscaría formalizar e institucionalizar el panamericanismo aprovechando el ambiente festivo de la celebración del Centenario de la Independencia de Argentina. Se trataba de una coyuntura, pues esta nación había sobresalido como uno de sus más fuertes detractores en los encuentros interamericanos anteriores (Morgenfeld 2009).

6 Roque Sáenz Peña fue delegado a las Conferencias panamericanas de México y Río de Janeiro; asumió la presidencia de Argentina en 1910 en plenas fiestas del Centenario de la Independencia y durante la realización de la iv Conferencia Panamericana. Publicó Los Estados Unidos en Sud-América. La Doctrina de Monroe y su evolución, libro en que lanzó acerbas críticas a dicha postura. Véase Andrés Kosel 2015: 29 y 30.

Sobre este tema véase Rodríguez y Reyes 2015: 195-213.

8 Para mayor profundidad véase Perkins 1955. 
En este foro multilateral de 1910, enmarcado en el ambiente festivo, se trabajaría alrededor de una agenda de fortalecimiento de las relaciones diplomáticas y se evitarían los temas que pudiesen desatar tensiones y confrontaciones. Esta cuestión cobraba especial interés para Estados Unidos, por lo que se empeñó en que, al interior de las Conferencias, no se incluyesen temas controversiales, como la intervención que se estaba desarrollando en Cuba y en Nicaragua. Aún más, los diferentes países latinoamericanos, México incluido, estuvieron de acuerdo en que fuese Buenos Aires la sede de la Cuarta Conferencia Internacional Americana.

Ahora bien, el año 1910 obliga a detenerse en la circunstancia mexicana, puesto que corresponde a una coyuntura crítica para el régimen de Porfirio Díaz. Se intensificaron los movimientos de oposición "tumultuosos" a decir de la prensa, ya que cobraron fuerza las acciones de los grupos magonistas y maderistas, al mismo tiempo que arreciaron las pugnas y el divisionismo al interior del círculo político porfirista. A pesar de este resquebrajamiento institucional, el gobierno desplegó una política exterior activa proyectando la imagen de una nación ordenada, estable y que cumplía con sus compromisos internacionales. Sobre todo, para el régimen de Díaz estaba en juego el actuar diplomático de la administración de Howard Taft ${ }^{9}$ Philander Knox ${ }^{10}$ respecto de las actividades de los grupos maderistas en suelo estadounidense.

En este escenario particular de las relaciones México-Estados Unidos, evidentemente, el gobierno mexicano comprendió el interés marcado de Washington por no abordar temas que suscitaran controversia entre los representantes de las naciones americanas, tanto como aquellos que lastimaran sus intereses, los de potencias europeas o de países aliados como Inglaterra. Luego entonces, la agenda se centraría en cuestiones de política regional: celebrar el Centenario de las gestas independentistas

9 La dupla Taft-Knox buscaba la promoción de los intereses comerciales estadounidenses, así como impulsar un crecimiento financiero en América Latina a través de la "Dollar Diplomacy".

${ }^{10}$ Knox sobresalió por promover la democracia y la estabilidad económica, lo hacía partiendo de la creencia de que los gobiernos democráticos son impulsores de la libertad comercial y la apertura comercial. 
en Hispanoamérica y, por encima de todo, no incluir temas controversiales. ${ }^{11}$ Estados Unidos temía que durante el cónclave se pudiese dar un pronunciamiento colectivo contra sus constantes intervenciones en el Caribe, Centroamérica y, en especial, contra el intervencionismo militar que estaba llevando a cabo en Nicaragua. ${ }^{12}$

\section{LA DOCTRINA MONROE EN LA PRENSA Y LA DIPLOMACIA MEXICANA}

La confección del programa estuvo a cargo de una comisión ex profeso, a través de la cual Washington buscaba controlar la agenda interamericana. Naturalmente, los intereses de la política exterior estadounidense variaron, dependiendo del país latinoamericano que fungiese como sede de dichos encuentros multilaterales, y sus resolutivos e impacto dependieron de las coyunturas, tanto como de las respuestas negativas o favorables de sus contrapartes latinoamericanas a las propuestas de Estados Unidos. Es decir, a lo largo de las conferencias celebradas a principios del siglo xX ganaron relieve las posturas y los intereses nacionales de los países del continente. Se generaron discursos y posicionamientos antiestadounidenses, e incluso alrededor de las Conferencias se fueron configurando una serie de textos antimonroístas. Con todo este contradictorio telón de fondo, la reunión de Buenos Aires se llevó a cabo desde el 12 de julio hasta el 30 de agosto de 1910.

La comisión estadounidense para diseñar el programa estaba integrada por notables miembros del mundo de la política, las finanzas, la cultura y la educación: Andrew Carnegie, el senador Stephen Elkins; James B. Mcreary, los diputados Charles B. Landis y James L. Salyden; el subsecretario de Estado Robert Bacon, el general Alfred G. Bates, Benjamin Ide Whesler, presidente de la Universidad de California, así

11 Los países participantes fueron Argentina, Brasil, Colombia, Costa Rica, Cuba, Chile, Ecuador, El Salvador, Estados Unidos, Guatemala, Haití, Honduras, México, Nicaragua, Panamá, Paraguay, Perú, República Dominicana, Uruguay y Venezuela.

12 Para profundizar sobre el tema véase Rodríguez 2013. 
como Edmund J. James, Paul Reinech y L. S. Rowe de la Universidad de Pennsylvania; William I. Buchanan, John Barrett, director de la Oficina Internacional de las Repúblicas Americanas; por último, William E. Curtis y Henry White.

La inclusión de los representantes de las universidades constituía la expresión del inicio de un intercambio entre las instituciones de educación superior latinoamericanas y las estadounidenses, en particular la asistencia de profesores iberoamericanos a cursos de verano en Estados Unidos y la enseñanza del idioma español, mismo que sería complementado con la formalización de la biblioteca Colón, especializada en América Latina. $^{13}$

Cabe señalar que participaron del convite panamericano la mayoría de las naciones, a excepción de Bolivia, que había roto relaciones diplomáticas con Perú y Argentina. Del país anfitrión hay que destacar el cambio de actitud de su representante, Epifanio Portela: si bien contrario a las anteriores reuniones, mostró una muy buena disposición y llegó a afirmar "que la República Argentina no tiene puntos de programa que sugerir a la Conferencia; que discutirá los que se ofrezcan y que, en caso necesario, prestará todos los buenos oficios que estén en su mano para el éxito de la reunión y la ejecución de sus resoluciones". ${ }^{14}$

A partir del informe del presidente de la comitiva estadounidense, Henry White, sabemos que la Conferencia se inauguró con el debido protocolo, y para beneplácito de los delegados de Washington. En el discurso de bienvenida se hizo alusión a la naturaleza benéfica de la Doctrina Monroe:

The minister of foreign affairs delivered an interesting speech, cordially welcoming to Buenos Aires the delegates of the various countries represented at the conference, alluding to the work of this and of previous conferences

13 Valga mencionar que este intercambio académico-cultural se realizaba con Cuba y Puerto Rico desde la guerra de 1898.

14 Archivo Histórico Genaro Estrada de la Secretaría de Relaciones Exteriores AHGE-SRE, legajo 184, Cuarta Conferencia Panamericana, foja 29. 
and referring in eulogistic terms to the Monroe doctrine, in which he said the people of the Argentine Republic had always been firm believers. ${ }^{15}$

Efectivamente, las catorce comisiones se reunieron de acuerdo con la agenda, previamente establecida y aprobada por los delegados, de manera que no había margen para incorporar nuevos asuntos. De este modo, los participantes se circunscribieron a revisar los temas abordados en la Tercera Conferencia, con la buena intención de "mejorar los puntos sustanciales de las materias deliberadas y enmendar los errores cometidos". ${ }^{16}$ Lo que ya se había convenido era buscar los medios para codificar y reglamentar convenios en materia de cooperación internacional. ${ }^{17}$

$\mathrm{Al}$ interior de estas comisiones se alcanzaron resolutivos relacionados principalmente con los mecanismos de uso y preservación de los recursos naturales, políticas sanitarias, así como derechos de propiedad intelectual e intercambio de profesores universitarios. Se resolvió además a favor del Ferrocarril Panamericano, cuyo proyecto de construcción y presupuesto le fue encomendado a una comisión formada ex profeso (El Imparcial, 12 de agosto de 1910). De acuerdo con Leandro Morgenfeld:

Esta cuarta reunión de las Repúblicas Americanas transcurrió en un clima de inusual armonía entre las representaciones argentina y norteamericana. Fueron tratados una serie de temas tales como el establecimiento de servicios de correo y pasajeros más rápidos para agilizar el servicio interamericano y de un ferrocarril interamericano, las políticas sanitarias, los derechos de propiedad intelectual y patentes comerciales e intercambio de profesores universitarios. ${ }^{18}$

15 "El ministro de Relaciones Exteriores pronunció un interesante discurso, dando la bienvenida cordialmente a Buenos Aires a los delegados de los distintos países representados en la conferencia, aludiendo a la labor de ésta y de conferencias anteriores y refiriéndose en términos elogiosos a la Doctrina Monroe, en la que dijo que el pueblo de la República Argentina siempre había sido firme creyente" (traducción del editor). Véase Barrett 1910.

16 AHGE-SRE, Reservada, Salado Álvarez a Mariscal, L-E-184, Washington, 15 de febrero de 1909, foja 1.

17 Archivo Histórico Genaro Estrada de la Secretaría de Relaciones Exteriores AHGE-SRE, legajo 184, Cuarta Conferencia Panamericana, foja 128.

18 Véase Morgenfeld 2007. 
Es decir, los delegados alcanzaron acuerdos en temas relacionados con la agilización del intercambio interamericano. ${ }^{19}$ En cuanto a la comitiva mexicana, conformada por Victoriano Salado Álvarez, Luis Pérez Verdía, Antonio Ramos Pedrueza y Roberto A. Esteva Ruiz (Marichal 2002), esta contribuyó en la redacción de las resoluciones tendentes a mejorar el comercio directo entre las naciones americanas, con reglamentos recíprocos, la unificación del sistema de pesas y medidas, al igual que el establecimiento de líneas de vapores más económicas y eficientes. También los delegados mexicanos colaboraron en el proyecto para la reorganización de la Oficina Internacional de las Repúblicas Americanas; por cierto, esa denominación cambió a Unión Panamericana y permaneció hasta el surgimiento de la Organización de Estados Americanos (OEA).

Otro resolutivo de esta conferencia continental consistió en mantener vigente el Tratado sobre el Arbitraje de Reclamaciones Pecuniarias, firmado en la Segunda Conferencia celebrada en la Ciudad de México. Como lo establecía el informe de los delegados mexicanos, este era el asunto que encerraba un "altísimo y palpitante problema del Derecho Internacional". Por esta razón y para no provocar desavenencias en el cónclave ni posibles reclamaciones de potencias europeas, como Inglaterra,

19 AHGE-SRE, Informe que rinde a la Secretaría de Relaciones Exteriores la Delegación Mexicana-Salado Álvarez presidente, Luis Pérez Verdía, Antonio Ramos Pedrueza y Roberto A. Esteba Ruíz, enviado a la Cuarta Conferencia Internacional Americana, reunida en la ciudad de Buenos Aires, Argentina, L-E-188 (I), México, 3 de diciembre de 1910, f. XX. El programa de la Iv Conferencia incluyó la siguiente agenda: 1. Celebración de la independencia y del centenario nacional, 2. Convenciones y resoluciones de la Tercera Conferencia que se celebró en Río de Janeiro, 3. Comisiones Panamericanas, 4. Oficina Internacional de las Repúblicas Americanas, 5 . Acta de reconocimiento al Sr. Andrew Carnegie por su generoso donativo del nuevo edificio de la oficina de las Repúblicas americanas, 7. Uniformidad de los reglamentos de aduana, 8. Uniformidad de censos, 9. Establecimiento de medios de comunicaciones más rápidos, por vapores entre las repúblicas, 10. Policía sanitaria y cuarentena, 11. Patentes, marcas de fábrica y propiedad literaria, 12. movilidad para profesores y estudiantes entre las universidades americanas, 13. Resolución del congreso científico de Santiago de Chile, 14. Acordar la forma en que las repúblicas de América celebrarán la apertura del Canal de Panamá y, finalmente, como punto número 15. Futuras conferencias. 
se resolvió que, en caso de diferendo, las partes contenciosas acudirían al Tribunal de La Haya (Pérez 2012).

Efectivamente, el cobro coercitivo de las deudas constituía un asunto de tal relevancia que ponía en juego la soberanía política y territorial de las naciones latinoamericanas, entre las cuales existían conflictos fronterizos, de larga data. ${ }^{20}$ En el ámbito económico-comercial se vislumbraba también la necesidad de uniformar y simplificar las regulaciones y derechos aduaneros, así como establecer oficinas aduanales para facilitar el intercambio mercantil, es decir, los delegados alcanzaron acuerdos en temas relacionados con el establecimiento de servicios de correo y de pasajeros más rápidos para agilizar el intercambio interamericano.

Una decisión de largo alcance la encarnó la institucionalización del proyecto integracionista estadounidense al aprobarse una moción para reorganizar la Oficina Internacional de las Repúblicas Americanas bajo el nombre de Unión Panamericana, y con un organigrama que colocaba al secretario de Estado estadounidense en la presidencia de este organismo interamericano. ${ }^{21}$ En este sentido: "se formalizó el establecimiento de Comités Panamericanos en cada uno de los países, adscritos a los Ministerios de Relaciones Exteriores. Estos entes tenían entre sus facultades promover ante los Congresos de sus naciones la ratificación de los convenios y tratados de las Conferencias, pero también proponer temas nuevos para los encuentros. Además, se fijó que el Consejo Directivo debía conformar una Comisión de Reforma, encargada de elaborar un plan para que la Unión Panamericana pudiera funcionar como un verdadero órgano multilateral" (Carrillo 2018: 69).

20 El bloqueo a los puertos venezolanos llevado a cabo por Inglaterra, Alemania e Italia a fines de 1902 en demanda del pago de empréstitos constituye un ejemplo de las implicaciones de esta convención en reclamaciones para la seguridad continental.

${ }^{21}$ Al respecto John Barrett (1910) explicó "the name of the bureau was changed to 'Pan American Union' while the name of the organization of American countries which supports the bureau was changed to the briefer form of 'Union of American Republics" "el nombre de la oficina se cambió a 'Unión Panamericana', mientras que el nombre de la organización de los países americanos que apoya la oficina se cambió a la forma más breve de "Unión de Repúblicas Americanas"' (traducción del editor). 
En México, estos acontecimientos eran seguidos con atención por el periódico oficioso El Imparcial, ${ }^{22}$ que informaba a un sector de la sociedad mexicana y formaba líneas de opiniones favorables al régimen de Porfirio Díaz, en plena antesala de la Revolución mexicana. A partir del análisis del discurso periodístico referente a este Encuentro panamericano, se identifican dos ejes de opinión en torno a los que se entretejió el corpus noticioso de este diario: el primero se refiere a la Doctrina Monroe, en tanto que el segundo tiene que ver con la actuación de los actores diplomáticos porfiristas. Evidentemente, nos interesa profundizar en los posicionamientos que se generaron alrededor del primer eje noticioso.

El Imparcial ostentaba una ideología liberal y positivista, que no solo se circunscribió a difundir el acontecer cotidiano, sino que era la expresión de sectores sociopolíticos con intereses muy determinados. Por ello consideraremos a las noticias como una serie de discursos y mensajes que pretenden incidir en la opinión pública y en la toma de decisiones políticas. Cuestión que acaparó la atención de la prensa internacional y mexicana como veremos a través del también denominado "primer diario moderno de México", subvencionado por el gobierno de Porfirio Díaz, de gran formato y amplia circulación.

En plena víspera de la Conferencia, El Imparcial informaba que los representantes de Venezuela tenían planeado emitir una protesta en contra de Estados Unidos por su intervencionismo en Centroamérica. Semejante acción podía entorpecer el buen curso de las relaciones interamericanas al interior del cónclave (El Imparcial, 7 de julio de 1910). Al mismo tiempo, se publicaron declaraciones de la administración porfirista, optimistas respecto a los resultados de la Conferencia (El Imparcial, 11 de julio de 1910); por último, se destacaba la importancia de este Congreso internacional para Washington, dado lo numeroso de su delegación en la capital argentina (El Imparcial, 12 de julio de 1910).

22 El Imparcial fue fundado el 11 de septiembre de 1896 por Rafael Reyes Spíndola, quien fungió como su director. Tuvo un gran formato y fue difusor de las noticias del momento, al igual que de temas de interés general. Contó con colaboradores como Amado Nervo, Juan de Dios Peza, Manuel Flores Ángel de Campo, Juan José Tablada, Heriberto Frías, Carlos Díaz Dufóo, Luis G. Urbina y Justo Sierra. Véase García 2003: 10. 
La inauguración de este Encuentro Panamericano ocupó un amplio espacio noticioso en las páginas de El Imparcial. Para sus editores existía la certeza de que dicha Conferencia sería "la base de un buen acuerdo social y político de las repúblicas americanas" (El Imparcial, 12 de julio de 1910), además de que exponían el programa al que debían de ceñirse los delegados. Después del acto de bienvenida, las planas del rotativo fueron pródigas en describir el protocolo y solemnidad del encuentro diplomático: "se llevó a cabo un brindis en conmemoración del Centenario de la Nación Argentina, y de la independencia de las Repúblicas americanas. Muchas de las cuales celebran su centenario en 1910, y fechas inmediatas" (El Imparcial, 13 de julio de 1910).

Otras noticias enaltecían la representatividad porfirista: "Trece de las catorce comisiones de la Conferencia Panamericana están integradas por delegados de México" (El Imparcial, 21 de julio de 1910) y con sentido de orgullo, resaltaban que "tres de ellas serán presididas por delegados de nuestra república" (El Imparcial, 17 de julio de 1910). Una vez concluidas las sesiones solemnes propias del inicio del foro multilateral, El Imparcial publicó noticias de fondo y reprodujo las críticas al programa de la Conferencia emitidas por la prensa extranjera. Por ejemplo, se informaba que el diario costarricense La República denunció la política de la Casa Blanca en torno a la agenda de la reunión, igualmente que exhortó a su gobierno a no enviar representantes para no malgastar los limitados recursos económicos con los que contaba.

Los operadores diplomáticos de Díaz estaban conformes con la agenda de la Conferencia, al igual que con la iniciativa de estrechar el intercambio comercial y centrarse en temas de índole económica y cultural. Por ende, los delegados seguían el programa en plena sintonía y armonía; sin embargo, la delegación estadounidense trató, junto con los representantes brasileños - Domicio Da Gama y Gastao de Cuhna-, de impulsar un pronunciamiento de apoyo a la Doctrina Monroe. Por supuesto, en el marco del primer centenario de vida independiente de varias de las naciones latinoamericanas, este hecho suscitó debates y tensiones entre los congresistas asistentes. 
El espectro noticioso de El Imparcial le brindó centralidad a la actuación de las delegaciones de Estados Unidos y de Brasil, tanto como a sus respectivos esfuerzos por otorgarle validez a la Doctrina Monroe dentro del derecho americano. No se escatimó espacio para cubrir la declaración de Henry White, presidente de la delegación estadounidense, sobre tal política: "concebida con el espíritu de las más amplia confraternidad americana, fue por su autor destinada a ser $[\ldots]$ una ley general que consagrara la libertad y la independencia de todas las naciones americanas". ${ }^{23} \mathrm{~A}$ pesar de todo, con el paso del tiempo este discurso se transformó de halo protector a vigía expansionista. Por eso mismo, los delegados de la Casa Blanca impulsaron de manera directa o a través de países como Brasil, la estrategia de continentalizar esta doctrina; estos esfuerzos por lograr un respaldo a la Doctrina Monroe al interior de la Cuarta Reunión Panamericana no disminuyeron.

En un extenso artículo El Imparcial se preguntaba: ¿Doctrina Panamericana en vez de Doctrina Monroe? Y explicaba tanto la iniciativa carioca de intentar obtener el apoyo de los delegados argentinos, como la reticencia de estos últimos, para concluir que un apoyo al postulado monroísta contravendría las atribuciones conferidas a los delegados participantes (El Imparcial, 18 de julio de 1910). Asimismo, daba cuenta de la inexistencia de consenso para que dicha declaración se llevara a cabo, ya que la mayoría de los países pretendían adecuarla a sus inquietudes. En particular, los diplomáticos de México, Chile, Venezuela y Argentina la rechazaron, no se adhirieron y mucho menos a la manera como la planteaba el Corolario Roosevelt. ${ }^{24}$

23 Henry White, presidente de la delegación estadounidense, manifestó reiteradamente que el presidente Monroe había sido movido por el espíritu de solidaridad americana y por los intereses comunes.

24 "El pensamiento originario pertenecía a la Delegación del Brasil, y sobre todo a su presidente Domicio Da Gama, ministro de sus país en Buenos Aires; pero de una parte, dificultades que por ese tiempo había entre el Brasil y Argentina, y de otra el propósito claramente manifestado de la República de Chile, de que podría traerle por sus antiguas cuestiones con el Perú, hizo fracasar la tentativa del Brasil, que llegó a tener en algún momento buena cantidad de partidarios y ascendiente muy conside- 
La delegación mexicana se mostró dispuesta a suscribir una adopción de la doctrina Monroe, pero solo lo haría en el sentido de la declaración presidencial expuesta en el mensaje del presidente Díaz al Congreso Federal, en ocasión de su informe anual de labores en 1896 (Rodríguez 2008). En el mismo sentido y en otras notas, El Imparcial informaba de la posibilidad de que Brasil redoblase esfuerzos en favor de la doctrina a través de una alianza con Chile, y que de este modo se obtuviera el voto de las dos terceras partes de los delegados. Con todas estas acciones se introducía oficialmente al monroísmo en el programa de la Conferencia. De acuerdo con este diario: "Los diplomáticos extranjeros, según se sabe, se han comunicado con sus gobiernos informándoles sobre estos acontecimientos los cuales ven una probable amenaza para el futuro, por lo que se refiere al comercio europeo" (El Imparcial, 22 de julio de 1910). Cabe agregar que Victoriano de la Plaza, ministro de Relaciones Exteriores de Argentina, rechazó que la Conferencia pretendiera cerrar las relaciones entre América y Europa, también aclaró que mucho menos se pretendía apoyar a la Doctrina Monroe. ${ }^{25}$

Para El Imparcial, la Conferencia revestía un interés político internacional, debido a las implicaciones de validar la Doctrina Monroe en todo el continente, sobre todo si resultaba reconocida a través de una convención o resolución, y si esta sucedía gracias a la iniciativa brasileña: llegaría "a tener en algún momento buena cantidad de partidarios y ascendiente muy considerable entre los delegados". ${ }^{26}$ Por ello no resulta fortuito que los editores de este rotativo se enfrascaron en disquisiciones sobre esta doctrina e informaran a sus lectores que:

Las opiniones están divididas sobre las ventajas o desventajas que presentaría el debate, pretendiendo unos la admisión de dicho asunto a la Conferencia $[. .$.$] señalaría una gran época en la historia de las Américas, y otros$

rable entre los Delegados." Rollo 2 Cuarta Conferencia Internacional Panamericana. Ciudad de Buenos Aires, del = I-E-186 AL = L-E 188.

25 Véase Cuarta Conferencia Internacional Americana. Diario de sesiones (Pérez 2012: 71).

26 Rollo 2 Cuarta Conferencia Internacional Panamericana. Ciudad de Buenos Aires, del $=\mathrm{I}-\mathrm{E}-186 \mathrm{AL}=\mathrm{L}-\mathrm{E} 188$. 
opinan que traería complicaciones inútiles, dando lugar a que las pequeñas Repúblicas descontentas dirigieran ataques a los Estados Unidos (El Imparcial, 23 de julio de 1910).

Parece claro que se referían a las repúblicas centroamericanas. Asimismo, reprodujeron una noticia del periódico argentino La Razón, en la que se afirmaba que Argentina, Brasil y Chile pretendían formar una alianza para contrarrestar los actos de Estados Unidos, principalmente los que estaban teniendo lugar en Cuba y Nicaragua. ${ }^{27}$ El Imparcial también notició la existencia de otro frente opositor a las políticas de la Casa Blanca, abierto por la delegación venezolana. A él le atribuía la propuesta de que el presidente de la mesa directiva de la Oficina Internacional de las Repúblicas Americanas fuera electo cada tres meses entre los delegados latinoamericanos, en vez de que siempre lo encabezara el secretario de Estado estadounidense (El Imparcial, 23 de julio de 1910). Se trataba así de una crítica al carácter permanente de la Oficina de la Unión Panamericana bajo la tutela de Washington.

El informe de la Delegación Mexicana en la Cuarta Conferencia a la Secretaría de Relaciones Exteriores respecto a la adopción de la Doctrina Monroe dio cuenta de los diversos posicionamientos: el primero consistió en enviar un voto de agradecimiento y de simpatía a Estados Unidos en razón del postulado Monroe y de la "buena voluntad que constantemente ha ejercitado a favor de los pueblos americanos" ${ }^{28}$ Mientras que el segun-

27 En el mismo sentido, la coyuntura de la revolución en Nicaragua de 1909-1910 marcó la línea editorial de El Imparcial en contra de la política de Estados Unidos en Centroamérica. Por ello se incluyeron en él noticias del conflicto militar y se llegaron a publicar afirmaciones, sin sustento, por no mencionar su fuente, de que se estaban fraguando en territorio centroamericano ciertas alianzas en contra de Estados Unidos.

28 De acuerdo con el informe del presidente de la representatividad mexicana, Victoriano Salado, "Tres pareceres predominaron en el seno de la asamblea. Consistió el uno en el envío de un voto de agradecimiento, simpatía y amistad a la República de los Estados Unidos en razón de los oficios de cariñoso auxilio y buena voluntad que constantemente ha ejercido en favor de los pueblos americanos. Pensaron otros delegados que semejante modo de proceder resultaría inadecuado, ya que produciría sospechas en Europa y no sería suficiente realizar el objeto que se deseaba; por eso se indicaron que debía adoptar la Conferencia, en términos claros y sencillos, la primi- 
do planteamiento consideraba esa declaración como inadecuada y proponía que la Conferencia adoptara el postulado de Monroe en su primitiva declaración de 1823, sin reconocer las enmiendas realizadas a lo largo del tiempo; por último, se abogó por adoptarla de manera voluntaria. ${ }^{29}$

Indudablemente, la línea editorial del diario de Reyes Spíndola mostró a la Doctrina Monroe como una cuestión de política internacional muy discutida en la reunión panamericana; durante el mes de julio de 1910 El Imparcial incluyó los cablegramas de la sección "Noticias de todo el Mundo" tanto en la primera plana como en la sección editorial y en las columnas creadas ex profeso, referentes a los posicionamientos en torno al postulado Monroe. Desde luego, en esas páginas hubo un amplio espacio para los posicionamientos de los delegados, al señalar que los anfitriones, dado su papel, trataron de no confrontarse directamente con Estados Unidos ni con Brasil; en cambio adoptaron una postura diplomática frente al monroísmo, limitándose a expresar que "la política argentina no es ni americana ni europea, porque ella es universal y se nutre de contactos y armonía con todos los pueblos enlazados de la tierra" (El Imparcial, 2 de agosto de 1910).

Por su parte, la delegación chilena, a través de su ministro de Relaciones Exteriores, Alejandro Álvarez, declaró que el principio del presidente James Monroe, formulado en 1823, se había confundido y mal interpretado a través del tiempo; se había valorado positivamente su beneficio para las nacientes repúblicas americanas, y sin embargo, habiendo pasado casi un siglo de su enunciación, y dada la polííca expansionista de Estados Unidos, ese postulado podría causar tensiones políticas innecesarias con los países europeos y entre los propios países latinoamericanos. En la opinión de este ministro, aunque sí se reconoció el valor histórico que tuvo en el siglo pasado esta doctrina, a principios del siglo XX se le identificaba

tiva declaración del Presidente Monroe, sin distinción ni vacilaciones que parecerían una timidez o falta de ánimo." Rollo 2 Cuarta Conferencia Internacional Panamericana. Ciudad de Buenos Aires, del = I-E-186 AL = L-E 188.

29 En ella se estipulaba que las recién independizadas repúblicas no serían objeto de reconquista territorial de parte de las potencias europeas. 
con la política expansionista estadounidense hacia sus vecinos del área caribeña y centroamericana.

El debate aquí expuesto dio lugar para que en El imparcial se hicieran inserciones críticas, tanto a la propuesta de Brasil como a la de Estados Unidos. En relación con la postura carioca se publicó una nota referente a la actitud del delegado brasileño que, al encontrar resistencia a su iniciativa, se defendió declarando: "que no se pretende modificar la doctrina haciéndola extensiva a las demás naciones americanas [...] y que de ninguna manera debía tomarse como una manifestación contra Europa [...] en caso de que la extensión de la doctrina no sea aprobada por el voto de los delegados, será abandonada" (El Imparcial, 25 de julio de 1910).

En efecto, El Imparcial informó que la propuesta brasileña no prosperaba y sus esfuerzos por introducirla en el programa de la Conferencia habían fracasado, ya que "el señor Gama, delegado del Brasil, no ha podido encontrar una fórmula satisfactoria para Chile. La proposición nunca fue sometida a la consideración de la delegación argentina, sino sólo aisladamente a algunos miembros" (El Imparcial, 26 de julio de 1910). De igual modo, este periódico incluyó la defensa de los delegados brasileños, quienes resentían la oposición a su propuesta, así como las acusaciones en su contra de pretender obtener ciertas ventajas políticas sobre sus vecinos del cono sur, por lo que "han declarado de una manera enfática que su único deseo es el bienestar de los países americanos" (El Imparcial, 27 de julio de 1910). A este comentario se añadió la opinión personal del señor Gastao de Cunha: "la adopción de los principios de la Doctrina Monroe por todos los países de la América Latina contribuiría poderosamente para estrechar los lazos de unión y de amistad entre las Repúblicas hermanas del Nuevo Mundo" (El Imparcial, 28 de julio de 1910).

Resulta pertinente aclarar que la delegación mexicana informó a detalle a la cancillería y no perdió oportunidad para refrendar la doctrina Díaz de 1896, junto con el pronunciamiento colectivo de defensa. ${ }^{30}$ En cuanto a la delegación estadounidense, esta ofreció un banquete a los

30 Rollo 2 Cuarta Conferencia Internacional Panamericana. Ciudad de Buenos Aires, del $=\mathrm{I}-\mathrm{E}-186 \mathrm{AL}=\mathrm{L}-\mathrm{E} 188$. 
delegados; el brindis fue la ocasión para defenderse de los antimonroístas; sobre las acusaciones en su contra, el delegado declaró desafiante: "nadie se atrevería a decir que fueron al combate incitados por el mercantilismo o el lucro" (El Imparcial, 6 de agosto de 1910).

Los encabezados utilizados en El Imparcial nos permiten medir el pulso de las tensiones y confrontaciones que estaban teniendo lugar en un cónclave donde se suponía que solo tendrían cabida las celebraciones y los festejos del Centenario de la Independencia. Algunos de los títulos más recurrentes fueron los siguientes: "Alemania y la Doctrina Monroe", "Doctrina panamericana en vez de Doctrina Monroe", "Los delegados de Brasil, Chile y la doctrina Monroe", "Se discute la Doctrina Monroe", si bien en otros se enuncia simple y llanamente "La Doctrina Monroe". "La Doctrina Monroe en la conferencia". "Elogia la política el srio. Knox. La Doctrina Monroe". "El representante de la República de Argentina no es favorable a la adopción de la Doctrina Monroe; en cambio apoya la de Drago" (El Imparcial, 28 de julio de 1910). De esta forma, se fue desvaneciendo el afán brasileño por establecer alianzas y fungir como aliado continental de Washington, a través del relanzamiento de la Doctrina Monroe.

Ciertamente, la delegación anfitriona emitía un gran número de declaraciones, que eran publicadas en El Imparcial (24 de julio de 1910). ${ }^{31}$ En un extenso artículo se reprodujo la posición argentina, que fue clara y enfática al afirmar:

No creo factible la adopción del monroísmo como doctrina panamericana, ni mucho menos le concedo valor efectivo en los propósitos que exhibe. A la Doctrina de Monroe puede dársele una extensa aplicación, o constreñírsele a casos inseguros, precisamente por la vaguedad con que fue expuesta por el ex presidente la Unión Americana. El monroísmo no ha tenido hasta ahora una ocasión propicia para manifestarse, y esto, agregado a las diferencias que existen entre varias de las naciones latinoamericanas, ha dificultado su adopción en los términos en que la propone la delegación brasileña

31 'La Prensa' en un enérgico editorial discute hoy lo relativo a la introducción de la Doctrina Monroe en el programa de la Conferencia, y apoya la política actual de los Estados Unidos, diciendo que Mr. Knox ha demostrado ser un político hábil y que siempre ha evitado hacer sentir la autoridad de los Estados Unidos." 
[...]. Además, considero que la América no tiene nada que temer de las naciones europeas, y que, por tanto, se hace innecesaria la aplicación de una doctrina que no hallaría donde aplicarse. La Argentina le debe todo lo que tiene al viejo continente, y sus ligas son tan estrechas con las naciones europeas, que no se vislumbra ni la menor nubecilla que pudiera empañar el cielo de nuestras relaciones (El Imparcial, 28 de julio de 1910).

Para El Imparcial era importante difundir las opiniones generadas alrededor de los actores, de las políticas y la diplomacia estadounidense al interior del cónclave interamericano, ya que en última instancia era ese país el gran promotor de dicho encuentro continental. Naturalmente, el mayor peso de la atención periodística se centró en los primeros días de la Conferencia y recayó en la Doctrina Monroe. No obstante que durante el mes de agosto disminuyó la cantidad de notas acerca del monroísmo, este periódico mantuvo su línea editorial de rechazo, al reproducir artículos de la prensa extranjera y publicar noticias de fondo; además, se incluyó en extenso el ríspido intercambio epistolar entre el encargado de negocios de Argentina en México, Jacinto S. García y el embajador de Estados Unidos en México, Henry Lane Wilson. ${ }^{32}$ Este último le exigía al ministro argentino que publicase una carta en la cual se retractara de sus comentarios negativos sobre la Doctrina Monroe y la política exterior estadounidense. Cuestión que el diplomático, avecindado en la Ciudad de México, realizó señalando que El Imparcial había sacado de contexto su declaración; como respuesta, "el repórter" de este diario se mantuvo en lo afirmado. ${ }^{33}$

32 Este diplomático, de triste memoria, estuvo involucrado en los eventos que culminaron con el asesinato de Madero y Pino Suárez. Véase Suárez 1995.

33 En la inserción del Imparcial se abundaba "Al celebrar nuestras entrevistas para recoger opiniones relativas a la Doctrina de Monroe, no quisimos, por otra parte, hacer una algarada. Personas respetabilísimas, como el señor Embajador Wilson, el señor Ministro de Chile y el señor Encargado de Negocios del Brasil, se prestaron gustosos a colaborar con sus opiniones en un artículo serio y mesurado que tocaba un punto de altísima trascendencia para el Nuevo Continente. Tanto el señor Embajador Wilson, cuya entrevista fue publicada primero, como los señores Ministro de Chile y Encargado de Negocios del Brasil, no han encontrado - y esto no satisface- que sus conceptos hayan sido alterados por el repórter". El Imparcial, 2 de agosto de 1910. 
De manera extensa El Imparcial se refirió a las discusiones que involucraron a los delegados de Venezuela, Cuba y Brasil en lo tocante a las frases laudatorias, tanto como a la iniciativa de enviar un telegrama de felicitación y agradecimiento por las gestiones del exsecretario de Estado, Elihu Root en favor de las relaciones interamericanas. El reconocimiento abarcaba asimismo su Latin American Tour en 1906, en el marco de la Conferencia de Río de Janeiro. A esta propuesta se opuso el delegado venezolano, criticando el intervencionismo estadounidense en la región ${ }^{34}$ y proponiendo que se hicieran públicas las posturas de los delegados al interior de las comisiones. Por su parte, el delegado cubano, Carlos García Vélez, inmediatamente contestó "declarando, que no era conveniente que se publicara lo mucho que se había dicho sobre los diversos asuntos" (El Imparcial, 22 de agosto de 1910).

La inquietud de los editores de El Imparcial ante la crítica antiestadounidense se vio reforzada con la reproducción de artículos provenientes de la prensa extranjera. Del diario parisino Le Temps se publicaron posturas en las que manifestaba "la opinión de que la diplomacia americana no logró obtener un triunfo [...] y que los Estados Unidos no pudieron hacer desaparecer la desconfianza de las Repúblicas Latinoamericanas las cuales dice, consideran a la Doctrina Monroe como una espada de dos filos, uno de los cuales es el control americano por medio del "Big stick"' (El Imparcial, 30 de agosto de 1910).

34 La crónica informaba lo siguiente: "Hoy se produjo en el seno de la Conferencia Panamericana un incidente que indudablemente es el más sensacional de cuantos se registraron desde que principió sus sesiones. Ya en los momentos en que los delegados se retiraban de la sesión de hoy, que fue la sesión de clausura, el delegado del Brasil, señor Da Cunha los detuvo, y en un vibrante discurso propuso se enviara un telegrama especial al ex secretario de Estado americano Mr. Root, haciéndole presente el reconocimiento de la Conferencia por los benéficos resultados que tuvo su gira por la América del Sur, como una desaprobación de la táctica anti-americana del delegado de Venezuela, señor Sumetta, quien se refirió sarcásticamente a los señores Root y White y a la actual actitud del Departamento de Estado americano hacia los países latino americanos[...]. El Sr. Summetta expresó que muchos delegados se habían abstenido de expresar sus verdaderas opiniones durante las sesiones de la Conferencia". 


\section{A MODO DE CONCLUSIÓN}

Después de este esbozo documental y hemerográfico, podemos afirmar que el cuarto encuentro panamericano resultó de alta relevancia en las relaciones interamericanas con el establecimiento de la Unión Panamericana, ya que propiciaría el surgimiento de sociedades, agrupaciones, congresos, seminarios de naturaleza diversa: científicos, médicos, comerciales, educativos, sanitarios, entre otros, propiciando un intercambio cultural continental de alcances contemporáneos.

Asimismo, gran parte del corpus noticioso se centró no tanto en proporcionar una radiografía del cónclave interamericano, sino en brindar opiniones negativas sobre la política estadounidense hacia América Latina, enfatizando a la par su oposición a la Doctrina Monroe. Igualmente, la selección hemerográfica nos devela la pertenencia de El Imparcial a una prensa interesada en informar y formar opinión, sobre todo resulta evidente su papel de portavoz del régimen de Díaz en amplios sectores de la sociedad urbana de México. Este periódico mexicano publicó casi cotidianamente acerbas críticas en contra de la Doctrina Monroe y el panamericanismo. Su discurso no solo muestra su posicionamiento negativo, aquí abordado, sino también el de otros órganos periodísticos latinoamericanos y europeos en contra del expansionismo estadounidense.

A grandes rasgos, en el desarrollo de este ensayo hemos mostrado el énfasis puesto por este diario oficioso en difundir y hasta denunciar el intervencionismo estadounidense y los intentos de la mancuerna Washington-Río de Janeiro, cuyo objetivo consistía en impulsar un reconocimiento a la Doctrina Monroe dentro de la Conferencia Interamericana. Evidentemente, esta postura contrasta con la política cautelosa y a la expectativa que, se supone, debían guardar los delegados porfiristas en la capital de Argentina y que frente a la posibilidad de generalizar la Doctrina Monroe en el continente se vieron orillados a manifestar su oposición al Monroísmo, so riesgo de querellarse con su poderoso vecino. En este sentido, podemos deducir finalmente que la postura de la delegación mexicana fue anteponer la doctrina Díaz de 1896 como un pronunciamiento de defensa colectiva contra la intervención de todo poder foráneo. 
BIBLIOGRAFÍA

Aguilar Monteverde, Pedro Alonso. El panamericanismo; de la doctrina de Monroe a la Doctrina Johnson. Cuadernos Americanos (1965): 47-50.

Caicedo Castilla, José. El panamericanismo. Buenos Aires: Roque Depalma Editor, 1961.

Carrillo, Veremundo. México en la Unión de las Repúblicas Americanas. El panamericanismo y la política exterior mexicana, 1889-1942. Tesis de doctorado. México: Colegio de México, 2018.

CONNELl-SMith, Gordon. El sistema interamericano. México: FCE, 1982.

CORZO, DiANA. La política exterior mexicana ante la nueva doctrina Monroe. México: Instituto de Investigaciones José María Luis Mora, 2005.

Dallanegra Pedraza, LuIs. Relaciones politicas entre Estados Unidos y América Latina: ¿Predominio Monroísta o Unidad Americana? Buenos Aires: Edición del Autor, 1994.

DONOVAn, Frank. Historia de la Doctrina Monroe. México: Diana, 1966.

DulCi SPYER, TEREZA MARÍA. "Conferencias Panamericanas (1889-1928): la cuestión de la identidad". Actas de la Octava Reunión de Electrónicos ANPHLAC, Vitoria, España, 2008: 8.

E. Mowry, GEORGE. The Era of Theodore Roosevelt and the Birth of Modern America. 1900-1912. Nueva York: Harper Torchbooks, 1962.

FlaGg Bemis, SAmuel. La política internacional de los Estados Unidos, t. XI. Nueva York: Biblioteca Interamericana/The Lancaster Press, 1939.

GuAdaluPe García, ClaRa. El periódico El Imparcial. El primer diario moderno de México. 1896-1914. México: Centro de Estudios Históricos del Porfiriato, 2003.

Marichal, Carlos (coord.). México y las Conferencias Panamericanas 1889-1938. Antecedentes de la globalización. México: Secretaría de Relaciones Exteriores, 2002.

Martínez Fraga, Pedro. El Panamericanismo y su evolución. La Habana: Siglo XX, 1924. 
Morales Pérez, Salvador. Primera Conferencia Panamericana. Raíces del modelo hegemonista de integración. México: Centro de Investigación Científica L. Tamayo A. C., 1994.

MORGENFELD, LEANDRO ARIEL. "La oposición argentina a la organización panamericana impulsada por Estados Unidos (Segunda Conferencia, México, 1901-1902)". Temas de historia argentina y americana 15 (2009): 159-193.

MORGENFELD, LEANDRO ARIEL. "Argentina y Estados Unidos, 50 años debatiendo el panamericanismo". XI Jornadas Interescuelas/Departamentos de Historia. Universidad de Tucumán, San Miguel de Tucumán, Argentina, 2007.

PÉREZ Reyes, ELDA. "México en la IV Conferencia Panamericana", en María del Rosario Rodríguez Díaz y Carmen Alicia Dávila. Ideología, procesos políticos y manifestaciones artísticas del Porfiriato a la Posrevolución. México: Universidad Michoacana de San Nicolás de Hidalgo/ Secretaría de Cultura de Michoacán, 2012.

PERKIns, DeXTER. A History of the Monroe Doctrine. Boston: Litlle Library and Company, 1955.

PITA, AleXANDRA. "Panamericanismo y nación. La perspectiva de Samuel G. Inman". Anuario del Instituto de Estudios Histórico-Sociales Prof. Juan Carlos Grosso 32.1 (2017): 135-154.

Rodríguez, Rosario. "Percepciones mexicanas sobre la reafirmación de la Doctrina Monroe, 1895-1896 en el periódico El Nacional". Laura Muñoz (coord.). Mar adentro: espacios y relaciones en la frontera México-Caribe. México: Instituto Mora, 2008.

RODRÍGUEZ, ROSARIO. Una década de relaciones de Estados Unidos y Centroamérica. México: IIH/UMSNH, 2013.

RODRÍGUEZ, ROSARIO y O. REYES. "iLa Doctrina Monroe una política caribeña? Las percepciones de Estados Unidos y Brasil". Revista Brasileira do Caribe 31 (2015): 195-213.

RooT, EliHu. Latin America and the United States (Addresses). Cambridge: Harvard University Press, 1917. 
Salceda Olivares, Juan Manuel. México y el principio de no intervención en las Conferencias Internacionales Americanas, 1923-1933. Tesis de licenciatura. México, UMSNH, 2001.

SCHOULTZ, LARS, Estados Unidos: una historia de la política norte-americana y sus relaciones con América Latina. Bauru: EDUSC, 2000.

SuÁREZ, ANA ROSA. En el nombre del destino manifiesto. México: Instituto Mora, 1995.

Zusman, Perla. "Negociando representacionalmente el panamericanismo. Estados Unidos y Argentina en la exposición universal de Búfalo (1901)". Espaço e Cultura 29 (2011): 22-34.

\section{ARCHIVOS CONSULTADOS}

Archivo Histórico Genaro Estrada de la Secretaría de Relaciones Exteriores.

LE 184. Cuarta Conferencia Panamericana.

LE 188. Cuarta Conferencia Panamericana.

BARRETT, JoHn. The Report of the Director to the Fourth Pan-American Conference Held at Buenos Aires, Argentine Republic, July, 1910. The International Bureau of the American Republics, Washington, D. C., Printing Government, July, 1910.

Informe a la Secretaría de Relaciones Exteriores de la Delegación Mexicana enviada a la Cuarta Conferencia Internacional Americana, reunida en la ciudad de Buenos Aires, Argentina, México, 3 de diciembre de 1910.

Cuarta Conferencia Internacional Americana. Diario de sesiones, t. I, Buenos Aires, Est. Gráfico de A. de Martino, 1911.

Microfilm de la Cuarta Conferencia Internacional Panamericana, Ciudad de Buenos Aires, rollo 2, LE- 186-188.

HEMEROGRAFÍA

El Imparcial, Ciudad de México, julio-agosto de 1910. 